\title{
Assessing the Seismic Wavefield of a Wind Turbine Using Polarization Analysis
}

\author{
Rachel F. Westwood ${ }^{\mathrm{a}}$ and Peter Styles \\ Applied and Environmental Geophysics Research Group, School of Geography, Geology \\ and the Environment, Keele University, Staffordshire, ST5 5BG UK \\ ${ }^{a}$ Present Address: Learning and Professional Development Centre, Keele University, Keele, \\ Staffordshire ST5 5BG
}

Keywords: small wind turbine, polarization, signal processing, seismic waves, engineering, environmental, singular value decomposition

\begin{abstract}
Ambient seismic noise can often be seen as problematic, but with the right analysis can act as a tool to image the Earth. Wind turbines are known to generate low frequency vibrations, however, the wave types that are generated are currently unknown. Characterizing these vibrations will allow wind turbines to be used as a seismic source and be of value to geotechnical applications and seismic interferometry. This paper uses polarization analysis of the seismic wavefield around a small wind turbine to identify the type of wave being generated by the turbine and to clarify the source. The seismic data recorded $190 \mathrm{~m}$ from the wind turbine are processed using a window length of 0.1 seconds and bandpass filtered on a selection of frequency ranges. Polarization analysis is performed for two different wind speed ranges, in order to show the variation of wave characteristics between operational and non-operational modes of the wind turbine. Polarized surface waves are identified as the predominant wave type at blade rotation harmonics, making this work particularly relevant to multichannel analysis of surface waves and seismic interferometry.
\end{abstract}




\section{INTRODUCTION}

The Earth contains a rich field of ambient seismic vibrations from a broad spectrum of sources, many of them random and transient. These vibrations may be seen as problematic if they are of large amplitude and in particular frequency ranges, but with appropriate analysis they can act as tools to image the earth especially the shear wave structure of shallow to intermediate depth ranges, which are involved in engineering projects and infrastructure developments. Using these techniques can remove the need to deploy active sources which may require permission and accessibility. Individual and arrays of wind turbines are very efficient generators of low frequency harmonic vibrations which travel many kilometres [1]. These frequencies can be detrimental to sensitive scientific equipment, such as seismic monitoring stations [1] and Gravitational Wave Observatories $[2,3]$, but have value to geotechnical applications and seismic interferometry. Due to advancements in technology, each wind turbine type generates different frequencies and three-component ground motion recordings are critical for assessing the frequencies generated by a specific wind turbine.

Siting of wind turbines near roads and railways is becoming more popular. These types of sites are typically seismically noisy environments. Polarization analysis of the noise, by quantitatively describing the particle motion of the seismic wavefield, can aid in the identification of frequencies originating from the wind turbine or from other nearby sources. In addition, the oscillatory characteristic of the wave can be used, via polarization analysis, to identify the types of wave originating from the wind turbine(s): surface waves have an elliptical-retrograde characteristic, whereas the body wave has linear motion. Describing a defined source signal will enable wind turbines to be used as a source for 
research into ground structure and geomechanical properties, in a similar manner to seismic interferometry $[4,5]$ and multichannel analysis of surface waves (MASW) for geotechnical applications $[6,7]$.

Polarization analysis has been applied extensively in the field of earthquake seismology. Rayleigh wave polarization analysis has been used successfully to identify the orientation of sited Ocean Bottom Seismometers [8] and polarization analysis of ambient noise fields has been successful applied for mapping anisotropy of the subsurface (e.g. $[9,10,11,12])$, as it can be used in areas where natural seismicity is low [11]. Various approaches to the filtering of data using polarization analysis have been suggested $[13,14,15,16,17]$. The polarization analysis and equations presented in this paper are based on singular value decomposition (SVD) [16, 18, 19, 20].

In this paper, we use polarization analysis to successfully identify and distinguish between specific frequencies originating from a small wind turbine $(11 \mathrm{~kW})$ and those from a wind farm of large turbines $(660 \mathrm{~kW})$ five kilometres away. Additionally, we identify the types of waves originating from these sources.

\section{THE WIND TURBINE}

The wind turbine used for this study is a Gaia-Wind $13311 \mathrm{~kW}$ tubular tower wind turbine, located on a farm just outside Wigton in Cumbria, UK. This is a popular downwind, two blade wind turbine, mounted on an $18 \mathrm{~m}$ monopole. It has a rotor diameter of $13 \mathrm{~m}$ and operates at a constant speed of $56 \mathrm{rpm}$. 
The Gaia-Wind 133 has a cut-in wind speed of $3.5 \mathrm{~m} / \mathrm{s}$. Above this wind speed, the wind turbine has a rotation rate of $56 \mathrm{rpm}$ and is generating electricity. At a wind speed of 2.5 $\mathrm{m} / \mathrm{s}$, the wind turbine will start to turn to enable it to get up to speed prior to the cut-in wind speed. The cut-out wind speed, when the brake is applied to prevent damage to the wind turbine, is $54 \mathrm{~m} / \mathrm{s}$.

A combination of accelerometers and seismometers were used to monitor the vibrations from the wind turbine (Fig. 1). A single-component Guralp 5U accelerometer was attached horizontally to the wind turbine tower, one metre up from the base using magnets. A three-component Guralp 6TD seismometer was buried in a one metre deep and $30 \mathrm{~cm}$ diameter hole, $190 \mathrm{~m}$ from the wind turbine. The sensors were deployed as described in [21].

[Figure 1 about here.]

\section{METHODOLOGY}

The relationship between wind speed and seismic amplitude varies between wind turbines and frequencies [21]. Wind speed and wind direction data, at the wind turbine, are available for the same time period as the seismic data. Therefore, the data are filtered both on wind speed and frequency, as some frequencies may be more prominent at certain wind speeds.

The wind speed for the time of the monitoring varied between $0 \mathrm{~m} / \mathrm{s}$ and $7.8 \mathrm{~m} / \mathrm{s}$, with the wind speed remaining within a $0.5 \mathrm{~m} / \mathrm{s}$ range $($ eg $1 \mathrm{~m} / \mathrm{s}-1.5 \mathrm{~m} / \mathrm{s}, 1.5 \mathrm{~m} / \mathrm{s}-2 \mathrm{~m} / \mathrm{s}$ ) for an 
average of 10 minutes. Two wind speed ranges are selected $1 \mathrm{~m} / \mathrm{s}-1.5 \mathrm{~m} / \mathrm{s}$ and $5.5 \mathrm{~m} / \mathrm{s}$ $6 \mathrm{~m} / \mathrm{s}$ (when the wind turbine was not operational and when it was turning and generating respectively). The operation of the wind turbine is confirmed by examining the raw time series.

Multiple frequency bands, of approximately $0.1 \mathrm{~Hz}$ in width are analysed which corresponded to the peaks visible in the frequency spectra recorded on an accelerometer attached to tower and on the seismometer (Fig. 2). A 3rd-order Butterworth filter is used to bandpass filter the signal over a narrow frequency band.

[Figure 2 about here.]

Two frequency bands corresponding to blade rotation harmonics were selected for discussing in this paper. Additionally, a peak which is more visible in the seismometer ground vibration data, than on the tower, and does not correspond to the resonant frequencies or blade rotation harmonics, was also selected for discussion in this paper. This peak lies at $4-4.2 \mathrm{~Hz}$. It was of interest as it is known [1] that large wind turbine generate frequencies in this band, corresponding to the second bending mode of the tower, but from the results of Westwood et al. [21] it is unlikely that the Gaia-Wind turbine would be generating this frequency. Therefore, this signal was analysed in order to identify the source of the signal at this frequency.

For each frequency band, identically sized, overlapping time windows, the length of which is a compromise between stability and resolution, are applied to the data. If the window 
length is too short the analysis becomes unstable; whereas a long window length will smooth the results and decrease the resolution. Fig. 3 shows 100 seconds of data, analysed using four different time windows. The 0.015 second (Fig. 3a) and 0.05 second (Fig. 3b) windows are both noisy, whereas the 0.5 second window (Fig. $3 \mathrm{~d}$ ) loses some detail. The 0.1 second window length has a good balance of low noise and detail and was therefore selected as optimal for data from this wind turbine. Polarization analysis is performed on each window.

[Figure 3 about here.]

The matrix $\mathbf{X}=\left(x_{n}, x_{e}, x_{z}\right)$ contains the data from one time window. Singular Value Decomposition is performed iteratively on the matrix $\mathbf{X}$, to obtain three matrices, which when multiplied together define $\mathbf{X}$, such that $\mathbf{X}=\mathbf{U S V}^{\mathrm{T}}$ [20]. The columns of $\mathbf{V}$ contain orthonormal eigenvectors of the inner product of $\mathbf{X}$ with itself $\left(\mathbf{X}^{\mathrm{T}} \mathbf{X}\right)$. The diagonal elements of $\mathbf{S}$ contain the square roots of the corresponding eigenvalues, $\lambda_{1}, \lambda_{2}$, and $\lambda_{3}$. The columns of $\mathbf{U}$ are the orthonormal eigenvectors of the matrix $\mathbf{X} \mathbf{X}^{\mathrm{T}}$ [20].

If $\lambda_{1} \geq \lambda_{2} \geq \lambda_{3}$, then the eigenvector $E=\left(e_{1}, e_{2}, e_{3}\right)$, pointing in the direction of the largest amount of polarization, corresponds to the largest eigenvector, $\lambda_{1}$. The eigenvectors which point in the direction of the second and least amounts of polarization correspond to eigenvalues $\lambda_{2}$ and $\lambda_{3}$ respectively [20].

The components of $E$ are used to obtain the azimuth and dip (equations. 1 and 2 respectively) [14]. 


$$
\begin{gathered}
\theta=\tan ^{-1}\left(\frac{e_{2}}{e_{1}}\right), \\
\phi=\tan ^{-1}\left(\frac{e_{3}}{\sqrt{e_{1}^{2}+e_{2}^{2}}}\right)
\end{gathered}
$$

Both the azimuth and dip range from $-90^{\circ}$ to $90^{\circ}$. If both are $0^{\circ}$, this would indicate a vector pointing horizontally from the seismometer to the wind turbine.

The strength of polarization, $P_{s}$, is obtained from the first three eigenvalues $[14,22]$ using equation 3.

$$
P_{S}=1-\frac{\lambda_{2}+\lambda_{3}}{\lambda_{1}}
$$

If $P_{s}$ is close to 1 then there is only one component of polarization, whereas a result of 0 will mean that the largest component is as big as the sum of the other two and the motion is circular. Values in between indicate elliptical motion, e.g., a polarized Rayleigh wave gives $P_{s} \geq 0.5[14]$.

Body and surface wave arrival directions (azimuth and dip) can be determined by the polarization analysis of the signal recorded on a three-component seismometer. Love waves will appear predominantly on the horizontal, transverse component whereas Rayleigh waves will be mostly detected on the vertical and horizontal radial components. In a layered medium, linear body waves can be differentiated from elliptical Rayleigh waves using 2D polarization analysis of the vertical and radial components; however, an addition dimension is required in order to identify Love waves. Similarly, the transverse component is also required to identify SH (a secondary (or shear) wave polarized in the 
horizontal plane) and P-SV (a primary (or pressure) wave that has been reflected and converted to a shear wave polarized in the vertical plane) body waves [14].

A P-wave would generate an azimuthal angle in the direction of the wind turbine. When combined with a dip close to $0^{\circ}$ and $P_{s} \approx 0.5$, an azimuth of $\pm 90^{\circ}$ indicates a Love wave. Rayleigh waves are indicated by a $P_{s} \geq 0.5$ and a change in azimuth with time, generating a slope between $+90^{\circ}$ and $-90^{\circ}$. The dip would be required to be close to $0^{\circ}$ or trending in the same direction to the azimuth (Fig. 4).

[Figure 4 about here.]

By examining the wind speed data and combining the results for the azimuth, dip, and $P_{s}$, it is possible to establish whether the signal detected at a given frequency and wind speed is originating from the wind turbine, the azimuth, and the amplitude and wave type (particle motion).

\section{RESULTS}

\section{Operational wind speed}

All frequency ranges, relating to the peaks visible in the spectra (Fig. 2) were analysed over the same time period. Three of these frequency ranges are shown in Fig. 5 and Fig. 6; along with an interpretation of the incoming waves, for wind speeds between $5.5 \mathrm{~m} / \mathrm{s}$ and $6 \mathrm{~m} / \mathrm{s}$, when the wind turbine should be turning (the wind turbine normally operates at wind speeds between $3.5 \mathrm{~m} / \mathrm{s}$ and $54 \mathrm{~m} / \mathrm{s}$ ). Fig. 6 also contains results for wind speeds between 
$1 \mathrm{~m} / \mathrm{s}$ and $1.5 \mathrm{~m} / \mathrm{s}$ (less than the cut-in wind speed) for comparison to the operational wind speed.

The predominant azimuthal angle over all frequencies was found to be $\pm 90^{\circ}$; which when combined with the values of the dip and $P_{s}$, indicates the presence of surface waves originating from the direction of the wind turbine. This can be observed by comparing the highlighted segments in Figs. 5 \& 6 with the relevant sketch in Fig. 4.

[Figure 5 about here.]

[Figure 6 about here.]

In the $4 \mathrm{~Hz}$ to $4.2 \mathrm{~Hz}$ and $7.5 \mathrm{~Hz}$ to $7.7 \mathrm{~Hz}$ bands (Figs. $5 \mathrm{a} \& 6 \mathrm{a}$ ) the signal is more varied and polarized signals from other sources are evident. A combination of Love and Rayleigh waves can be seen originating from the direction of the wind turbine and also from a source 20 or 200 degrees away (due to an inherent $180^{\circ}$ ambiguity with the eigenvectors $[14,23]$ ). This is the direction of Great Orton wind farm, $5 \mathrm{~km}$ north east of the wind turbine (identified in Fig. 7 later).

The Great Orton wind farm consists of six Vestas V47 $660 \mathrm{~kW}$ wind turbines, providing a total capacity of $3.96 \mathrm{MW}$. Each turbine has a rotor diameter of $47 \mathrm{~m}$ and a hub height of between $40 \mathrm{~m}$ and $55 \mathrm{~m}$. Vestas V47 wind turbines are known to generate vibrations at frequencies between $4 \mathrm{~Hz}$ and $4.5 \mathrm{~Hz}$, depending on wind speed [1]. 
Unlike in earthquake seismology, where polarization analysis of the seismic field has been used considerably and where there is a seismic signal with distinctive phases of energy arrival, a wind turbine is a constant source with multiple types of waves arriving simultaneously and out of phase. In Fig. 5a, at around 270 seconds, a Rayleigh wave arrives from the direction of the wind turbine; however, an SV-wave arrives at around 280 seconds, masking the Rayleigh wave.

The $6.6 \mathrm{~Hz}-6.8 \mathrm{~Hz}$ analysis (Fig. 5b) indicates particle motion perpendicular to the source. However, these are not all surface waves as the dip is predominantly around $45^{\circ}$, and for some short periods of time close to $0^{\circ}$. The value of $P_{s}$ is generally greater than 0.5 , hence indicating a combination of surface and $\mathrm{SH}$ waves.

$\mathrm{SV}$ and P-SV waves (azimuth $=0^{\circ}$, dip $=40^{\circ}$ and high strength of polarization) from the direction of the wind turbine are present between 50 seconds and 70 seconds in the $7.5 \mathrm{~Hz}$ - 7.7 Hz analysis (Fig. 6a). These waves also occur at around 165 seconds to 180 seconds.

\section{Comparison to blade rotation harmonics}

The blade rotation frequency is calculated as a function of the rpm of the wind turbine and the number of blades. The Gaia-Wind 133 rotates at a constant speed of $56 \mathrm{rpm}$. This gives a blade rotation frequency of $0.93 \mathrm{~Hz}$. Harmonics occur at multiples of these frequencies. Polarization analyses were conducted for a selection of the harmonics of this frequency, two of which are shown in Fig. $5 \mathrm{~b}$ and Fig. 6a respectively. The prominent waves for each analysis were surface waves. However, for other frequencies visible in the spectra (Fig. 2) body waves are more identifiable. 


\section{Low wind speeds}

Fig. 6 shows a comparison of the polarization analysis results for wind speeds of $1 \mathrm{~m} / \mathrm{s}$ $1.5 \mathrm{~m} / \mathrm{s}$ (less than the cut-in wind speed) and $5.5 \mathrm{~m} / \mathrm{s}-6 \mathrm{~m} / \mathrm{s}$, for the frequency band 7.5 $\mathrm{Hz}$ to $7.7 \mathrm{~Hz}$.

At low wind speeds, the azimuthal variation is wide with a general spread of directions, whereas at higher wind speeds $(5.5 \mathrm{~m} / \mathrm{s}-6 \mathrm{~m} / \mathrm{s}$, Fig. 6a), the azimuth lies mostly between -10 and 10 degrees.

The dip, at low wind speeds, is generally in the $+/-80$ to 85 degree range and the strength of polarization is less than at the higher wind speed $(5.5 \mathrm{~m} / \mathrm{s}-6 \mathrm{~m} / \mathrm{s})$, by on average 0.2 . Combined these indicate that the signals from the wind turbine are not dominating the wavefield. At this wind speed, the analysis is showing background noise, which accounts for the variation in $P_{s}$.

\section{CONCLUSIONS}

This paper has shown how polarization analysis, using singular value decomposition, of the seismic wavefield, recorded on a three-component seismometer, can be used to characterize and identify the waves originating from a wind turbine. Surface waves have been identified as the prominent wave type for the blade rotation frequency and harmonics; however, body waves are also present at other frequencies. We have demonstrated that, by using the azimuth, peaks visible in the spectra can be identified as originating from sources other than the Gaia-Wind 133 wind turbine. This is further confirmed by examining potential sources and identifying the frequencies that are generated. 
Fig. 7 summarises the results of this paper and shows the location of the Great Orton wind farm in relation to the Gaia-Wind 133 wind turbine. Signals from the wind farm were identified using polarization analysis of the $4.1 \mathrm{~Hz}$ peak, visible in both spectra calculated from the data recorded on the turbine and on the seismometer $190 \mathrm{~m}$ away. The figure also shows the main polarized signals identified as originating from each site.

[Figure 7 about here.]

Additionally, we have shown that at low wind speeds, below the turbine cut-in wind speed, the seismic wavefield is dominated by background noise and contains a large variation in the strength of polarization.

This is the first study to investigate the wavefield around such a wind turbine using polarization analysis and has significant applications within geotechnical engineering and research into geomechanical properties and ground structure. This can be carried out in a similar manner to the fields of seismic interferometry and MASW, where sources of well characterised ambient noise are essential. Further work will involve applying the seismic data from the wind turbine in this way to more fully understand the applicability. Additionally, modelling of co-located sources for more complex locations will be carried out including investigations using synthetic seismograms and addressing the issue of mixtures and uniqueness. 


\section{ACKNOWLEDGEMENTS}

We would like to thank Gaia-Wind and the wind turbine owner for their support in this project. Thanks go to Nigel Cassidy and Sam Toon for their valued comments on the manuscript and to the reviewers, whose comments have significantly improved the paper. This paper draws on $\mathrm{PhD}$ research, entitled "Seismic Monitoring and Multiphysics Modelling of Ground-borne Vibrations from Small Wind Turbines," which was jointly funded by the Engineering and Physical Sciences Research Council (Grants EP/P502535/1 and EP/P503981/1) and a Keele University Acorn research grant. 


\section{REFERENCES}

[1] P. Styles, I. Stimpson, S. Toon, R. England and M. Wright, "Microseismic and Infrasound Monitoring of Low Frequency Noise and Vibrations from Windfarms: Recommendations on the Siting of Windfarms in the Vicinity of Eskdalemuir, Scotland," Keele University, Tech. rep., 2005. Available from: https://www.keele.ac.uk/geophysics/appliedseismology/wind/Final_Report.pdf

[2] R. Schofield, "Seismic Measurements at the Stateline Wind Project - And a Prediction of the Seismic Signal that the Proposed Maiden Wind Project Would Produce at LIGO," University of Orego, Tech. rep., 2002. Available from: http://www.ligo-wa.caltech.edu/ robert.schofield/windreport.pdf

[3] G. Saccorotti, D. Piccinini, L. Cauchie and I. Fiori, "Seismic Noise by Wind Farms: A Case Study from the Virgo Gravitational Wave Observatory, Italy," Bulletin of the Seismological Society of America, vol. 101, no. 2, pp. 568-578, Apr. 2011. doi: $10.1785 / 0120100203$

[4] N. M. Shapiro and M. Campillo, "Emergence of broadband Rayleigh waves from correlations of the ambient seismic noise," Geophysical Research Letters, vol. 31, no. 7, Apr. 2004. doi: 10.1029/2004GL019491

[5] H. Nicolson, A. Curtis, B. Baptie and E. Galetti, "Seismic interferometry and ambient noise tomography in the British Isles," Proceedings of the Geologists Association, vol. 123, no. 1, pp. 74-86, Jan. 2012. doi: 10.1016/j.pgeola.2011.04.002

[6] D. Penumadu and C. Park, "Multichannel Analysis of Surface Wave (MASW) Method for Geotechnical Site Characterization," in Earthquake Engineering and Soil Dynamics, Geo-Frontiers Congress 2005. Austin, Texas. 2005. doi: 10.1061/40779(158)3\#sthash.8Ut615wl.dpuf

[7] K. Tokeshi, P. Harutoonian, C. J. Leo and S. Liyanapathirana, "Use of surface waves for geotechnical engineering applications in Western Sydney," Advances in Geosciences, vol. 35, pp. 37-44, Jun. 2013. doi:10.5194/adgeo-35-37-2013

[8] J. C. Stachnik, A. F. Sheehan, D. W. Zietlow, Z. Yang, J. Collins and A. Ferris, "Determination of New Zealand Ocean Bottom Seismometer Orientation via Rayleigh-Wave Polarization," Seismological Research Letters, vol. 83, no. 4, pp. 704-713, Jul. 2012. doi: 10.1785/0220110128 
[9] M. Moschetti, M. H. Ritzwoller, F. Lin and Y. Yang, "Seismic evidence for widespread western-US deep-crustal deformation caused by extension," Nature, vol. 464, pp. 885-889, 2010. doi:10.1038/nature08951

[10] J. Adam and S. Lebedev, "Azimuthal anisotropy beneath southern Africa from very broad-band surface-wave dispersion measurements," Geophysical Journal International, vol. 191, pp. 155-174, 2012. doi: 10.1111/j.1365-246X.2012.05583.x

[11] N. Riahi, G. Boklemann, P. Sala and E. H. Saenger, "Time-lapse analysis of ambient surface wave anisotropy: A three-component array study above an underground gas storage," Journal of Geophysical: Solid Earth, vol. 118, pp. 53395351, 2013. doi: 10.1002/jgrb.50375

[12] M. M. Pischiutta, K. Savage, R. A. Holt and F. Salvini, "Fracture-related wavefield polarization and seismic anisotropy across the Greendale Fault," Journal of Geophysical Research, vol. 120, pp. 7048-7067, 2015. doi: 10.1002/2014JB011560

[13] E. A. Flinn, "Signal analysis using rectilinearity and direction of particle motion," Proceedings of the IEEE, vol. 53, no. 12, pp. 1874-1876, 1965. doi: 10.1109/PROC.1965.4462

[14] J. E. Vidale, "Complex polarization analysis of particle motion," Bulletin of the Seismological Society of America, vol. 76, no. 5, pp. 1393-1405, October 1986.

[15] M. Hobiger, C. Cornou, P. Bard and N. Le Bihan, "MUSIQUE: A quaternion-based array processing technique for surface wave polarization analysis," in Statistical Signal Processing Workshop (SSP), 2011. doi: 10.1109/SSP.2011.59677700

[16] O. Tiapkina, M. Landrø, Y. Tyapkin and B. Link, “Single-station SVD-based polarization filtering of ground roll: Perfection and investigation of limitations and pitfalls," Geophysics, vol. 77, no. 2, pp. V41-V59, Mar. 2012. doi: 10.1190/geo2011-0040.1

[17] K. Meza-Fajardo, A. Papageorgiou, F. Bonilla and J.-F. Semblat, "Modeling seismic surface waves through time-frequency analysis and group delay spectrum," in Proceedings of the 9th International Conference on Structural Dynamics, EURODYN 2014, pp. 572-582, 2014. ISBN: 978-972-752-165-4

[18] J. Park, F. L. Vernon and C. R. Lindberg, "Frequency dependent polarization analysis of high-frequency seismograms," Journal of Geophysical Research: Solid Earth, vol. 92, no. B12, pp. 12664-12674, Nov. 1987. doi:

10.1029/JB092iB12p12664 
[19] K. Bataille and J. M. Chiu, "Polarization analysis of high-frequency, threecomponent seismic data," Bulletin of the Seismological Society of America, vol. 81, pp. 622-642, April 1991.

[20] G. M. Jackson, I. M. Mason and S. A. Greenhalgh, "Principal component transforms of triaxial recordings by singular value decomposition," Geophysics, vol. 56, no. 4, pp. 528-533, Apr. 1991. doi: 10.1190/1.1443068

[21] R. F. Westwood, P. Styles and S. M. Toon, "Seismic monitoring and vibrational characterization of small wind turbines: A case study of the potential effects on the Eskdalemuir International Monitoring System Station in Scotland," Near Surface Geophysics, vol. 13, no. 2061, pp. 115-126, Mar. 2015. doi: 10.3997/18730604.2015001

[22] D. T. Nguyen, R. J. Brown and D. C. Lawton, "Polarization filter for multicomponent seismic data," Crewes. Tech rep. 1989. Available from: http://www.crewes.org/ForOurSponsors/ResearchReports/1989/1989-07.pdf

[23] N. Hendrick and S. Hearn, "Polarisation Analysis: What is it? Why do you need it? How do you do it?," Exploration Geophysics, vol. 30, no. 4, pp. 177-190, 1999. doi: 10.1071/EG999177

[24] O. Tiapkina, M. Landrø and Y. Tyapkin, "Single-station SVD-based Polarization Filtering - Theoretical and Synthetic Data Investigations," in 72nd EAGE Conference and Exhibition incorporating SPE EUROPEC 2010, 2010. doi: 10.3997/2214-4609.201401119

[25] R. F. Westwood, "Seismic monitoring and multiphysics modelling of ground-borne vibrations from small wind turbines," 2012. PhD Thesis. Keele University. 


\section{LIST OF FIGURES}

1. Map of the site. The Gaia-Wind 133 is identified by the star and the Guralp 6TD seismometer by the triangle. Inset: The location of the site within the UK.

2. Annotated frequency spectra using data recorded on the wind turbine (black line) and from the vertical component of a Guralp 6TD seismometer located $190 \mathrm{~m}$ from the wind turbine (dotted). The annotations indicate the blade rotation frequency and harmonics, as well as the 1st and 2nd resonant modes of the wind turbine, as identified in Westwood [24]. The highlighted areas are the three frequency bands discussed in this paper.

3. Polarization analysis results of data recorded near a Gaia-Wind 133 wind turbine for different period time windows: a) $0.015 \mathrm{sec}$ period, b) $0.05 \mathrm{sec}$ period, c) 0.1 sec period and d) $0.5 \mathrm{sec}$ period.

4. Sketch of the identification of different wave types that could be visible in the polarization analysis results

5. Results from performing polarization analysis on data recorded on a 6TD seismometer $190 \mathrm{~m}$ from a Gaia-Wind 133 wind turbine at wind speeds between $5.5 \mathrm{~m} / \mathrm{s}$ and $6 \mathrm{~m} / \mathrm{s}$ for three frequency bands: a) $4 \mathrm{~Hz}-4.2 \mathrm{~Hz}$ and b) $6.6 \mathrm{~Hz}-6.8$ Hz. Annotations and vertical dashed lines highlight different waves seen within the data which correspond to the sketches in Figure 4. A $0^{\circ}$ azimuth $(\theta)$ and dip $(\phi)$ indicate a vector pointing horizontally from the seismometer in the direction of the wind turbine.

6. Results from performing polarization analysis for data recorded on a 6TD seismometer 190m from a Gaia-Wind 133 wind turbine between $7.5 \mathrm{~Hz}$ and 7.7 
$\mathrm{Hz}$ and at wind speeds of a) $5.5 \mathrm{~m} / \mathrm{s}$ to $6 \mathrm{~m} / \mathrm{s}$ and b) $1 \mathrm{~m} / \mathrm{s}$ to $1.5 \mathrm{~m} / \mathrm{s}$. Annotations and vertical dashed lines highlight different waves seen within the data which correspond to the sketches in Figure 4. A $0^{\circ}$ azimuth $(\theta)$ and dip $(\phi)$ indicate a vector pointing horizontally from the seismometer in the direction of the wind turbine. At low wind speeds the azimuthal and strength of polarization variations are wide with a general spread of directions and strength respectively.

7. The location and direction of the Great Orton wind farm relative to the wind turbine (star) and seismometer (circle). Inset (top left): Location of the site (black dot) in the UK. Inset (top middle and bottom right): Polarized signals and frequencies seen as a result of the Gaia-Wind 133 turbine and the Great Orton wind farm. 


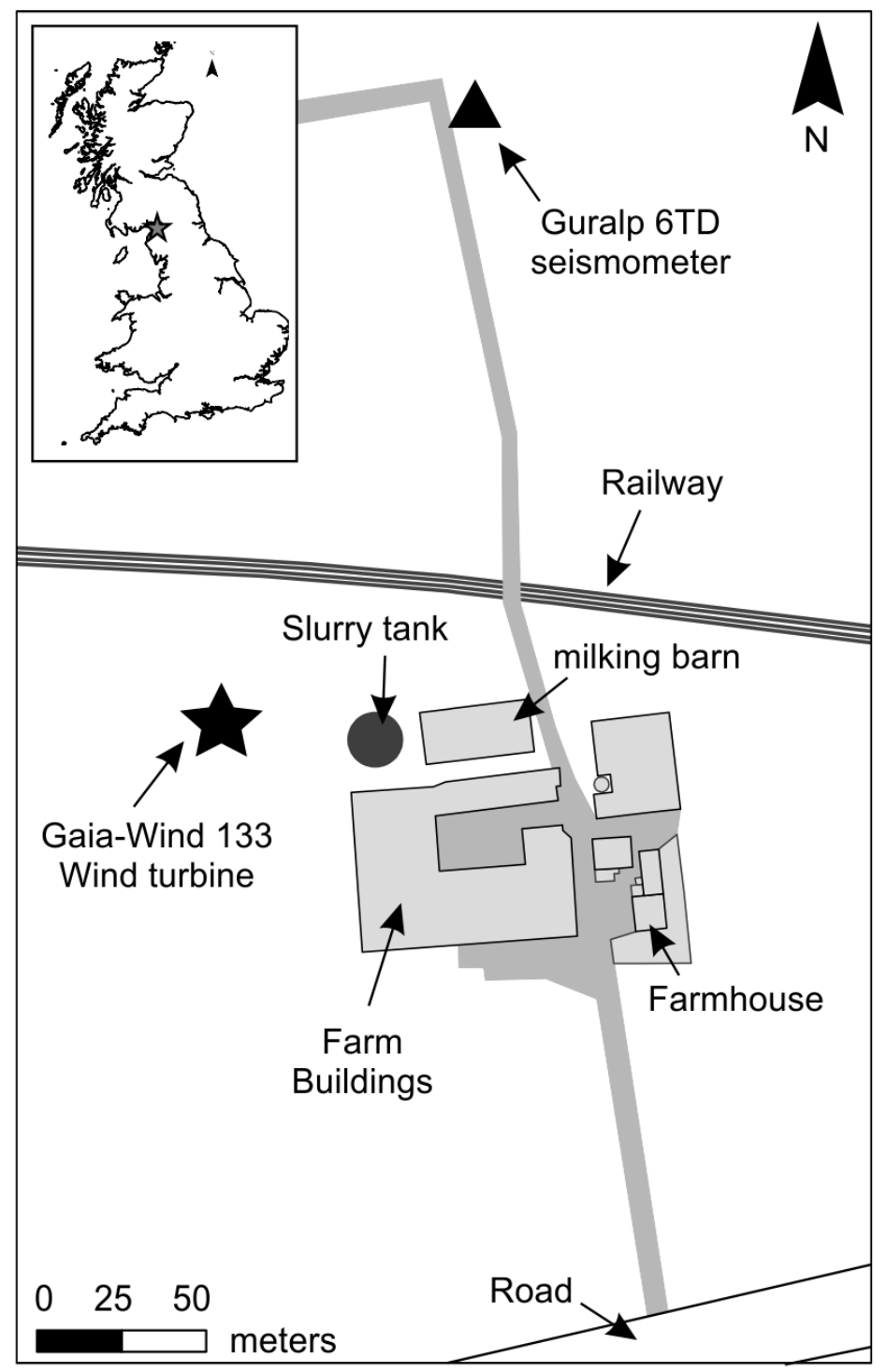

Figure 1: Map of the site. The Gaia-Wind 133 is identified by the star and the Guralp 6TD seismometer by the triangle. Inset: The location of the site within the $U K$. 


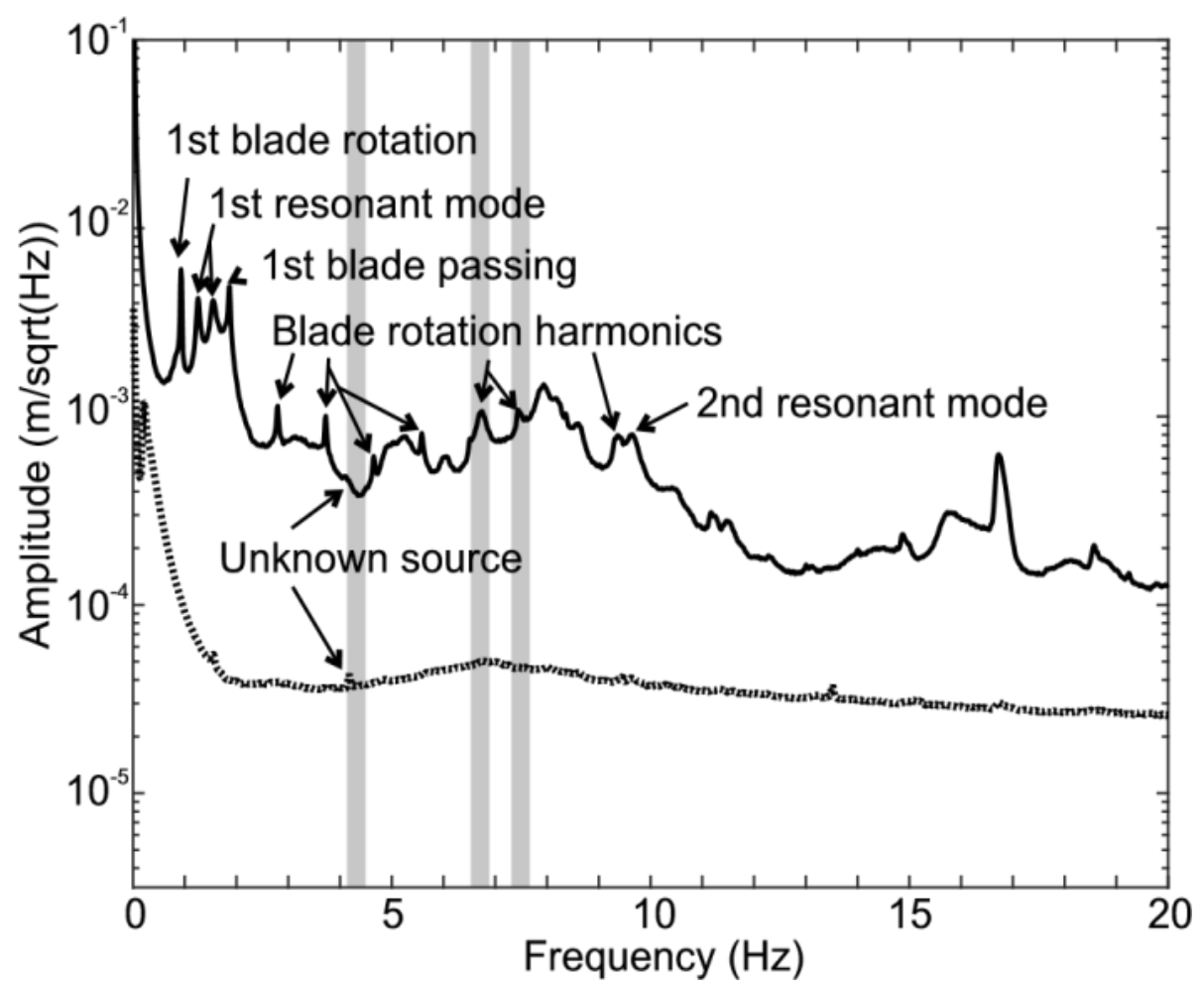

Figure 2: Annotated frequency spectra using data recorded on the wind turbine (black line) and from the vertical component of a Guralp 6TD seismometer located $190 \mathrm{~m}$ from the wind turbine (dotted). The annotations indicate the blade rotation frequency and harmonics, as well as the 1st and 2nd resonant modes of the wind turbine, as identified in Westwood [24]. The highlighted areas are the three frequency bands discussed in this paper. 


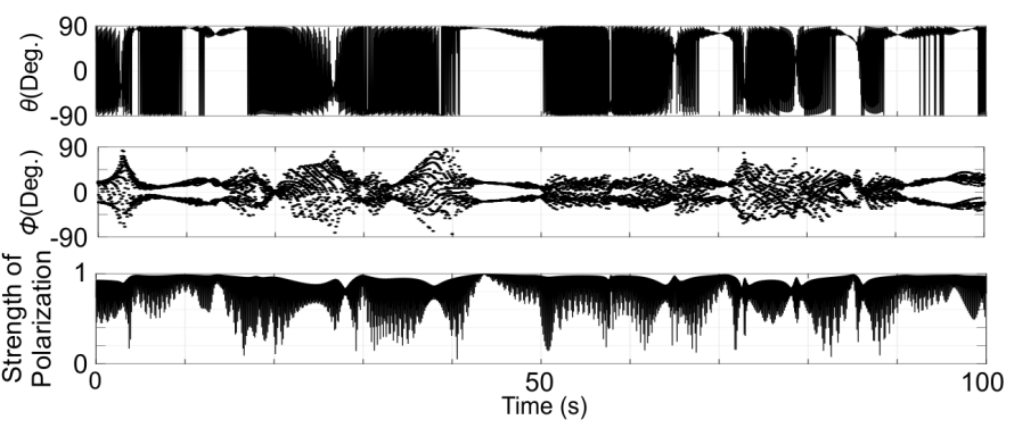

a. $0.015 \mathrm{sec}$ period

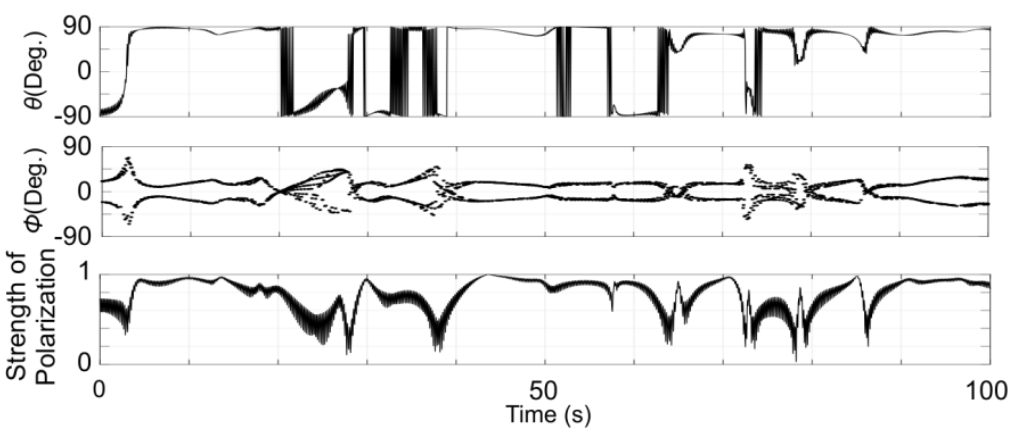

b. 0.05 sec period

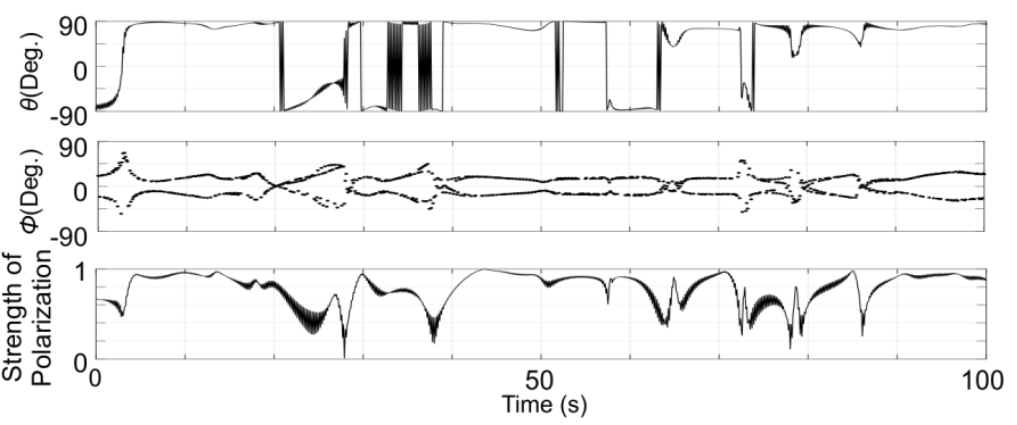

c. $0.1 \mathrm{sec}$ period

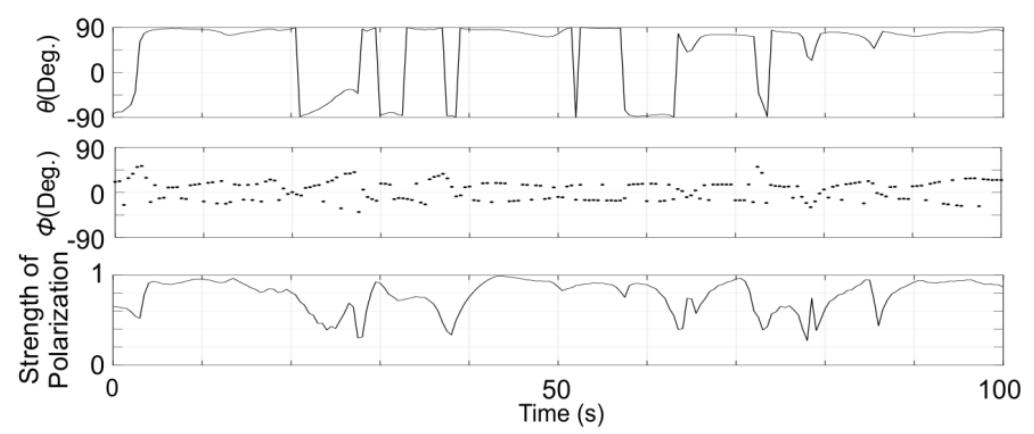

d. 0.5 sec period

Figure 3: Polarization analysis results of data recorded near a Gaia-Wind 133 wind turbine for different period time windows: a) $0.015 \mathrm{sec}$ period, b) $0.05 \mathrm{sec}$ period, c) $0.1 \mathrm{sec}$ period and d) $0.5 \mathrm{sec}$ period. 


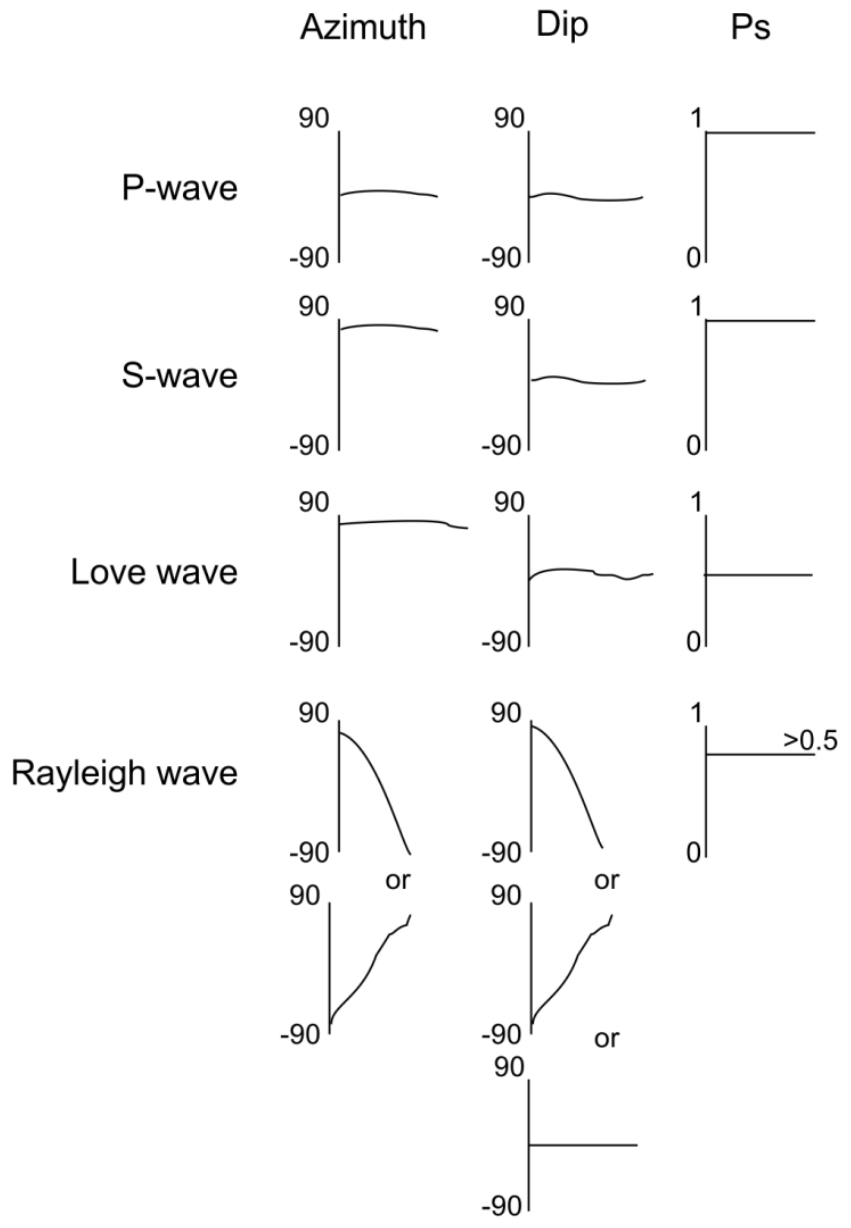

Note: It is posible that a signal close to 90 will jump between + and -90 degrees due to a 180 degree ambiguity. Therefore these are similar for the dip and azimuth
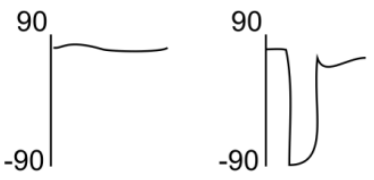

Figure 4: Sketch of the identification of different wave types that could be visible in the polarization analysis results 
a) $4-4.2 \mathrm{~Hz}$

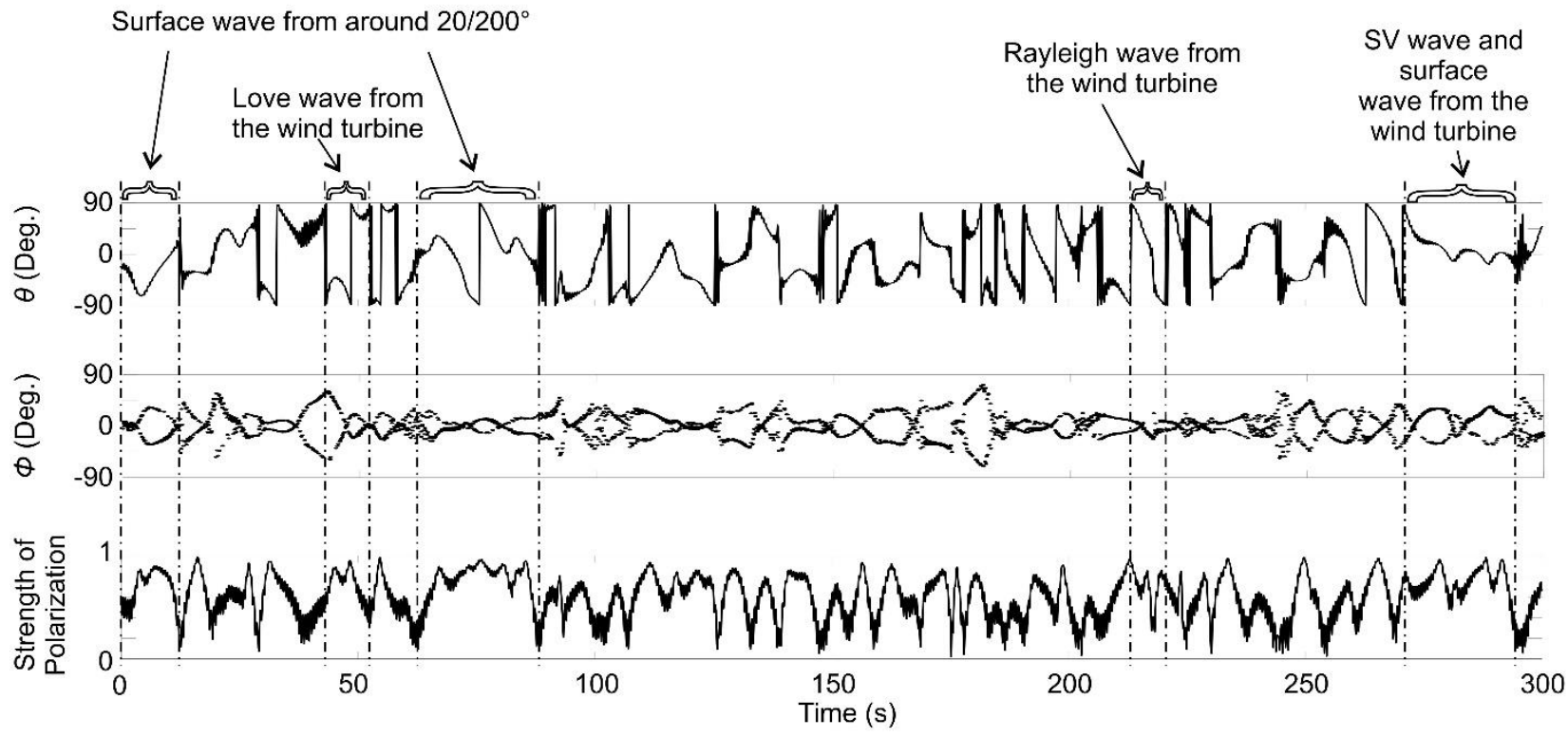

b) $6.6-6.8 \mathrm{~Hz}$

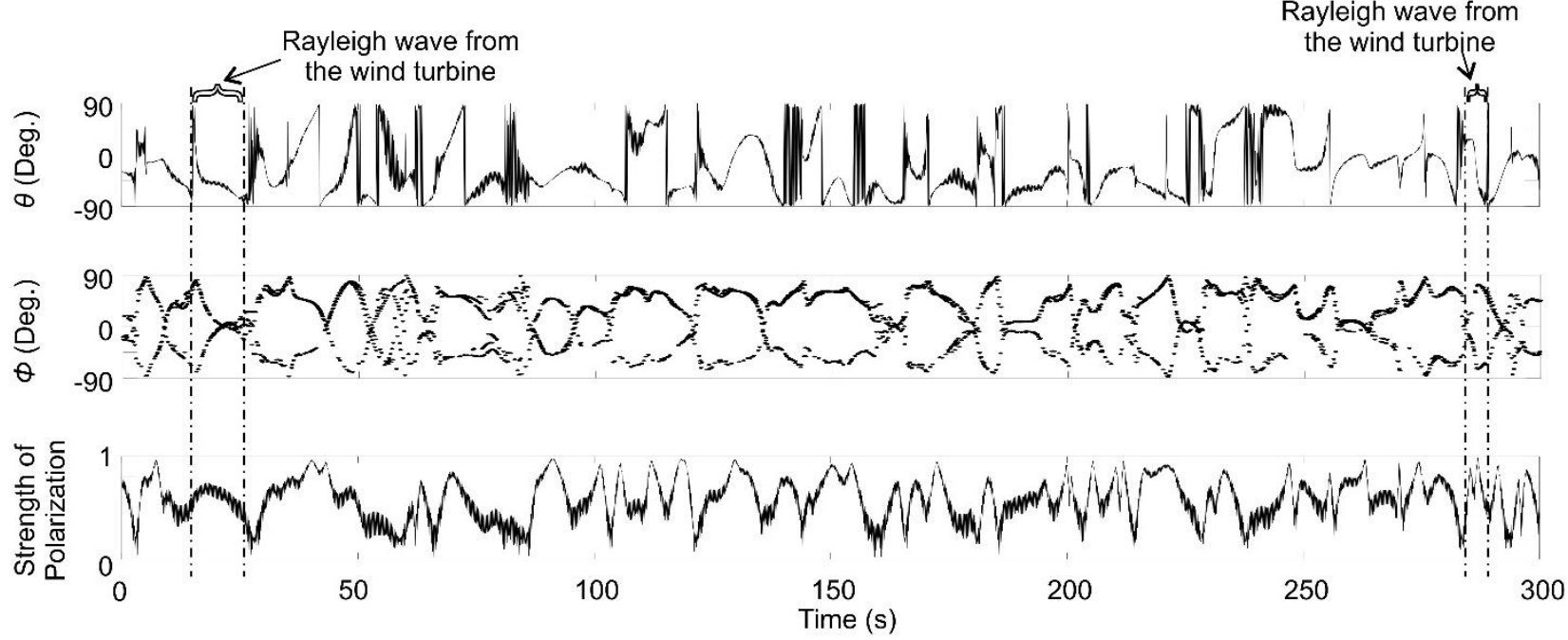

Figure 5: Results from performing polarization analysis on data recorded on a 6TD seismometer 190m from a Gaia-Wind 133 wind turbine at wind speeds between $5.5 \mathrm{~m} / \mathrm{s}$ and $6 \mathrm{~m} / \mathrm{s}$ for three frequency bands: a) $4 \mathrm{~Hz}-4.2 \mathrm{~Hz}$ and b) $6.6 \mathrm{~Hz}-6.8 \mathrm{~Hz}$. Annotations and vertical dashed lines highlight different waves seen within the data which correspond to the sketches in Figure 4. A $0^{\circ}$ azimuth $(\theta)$ and dip $(\phi)$ indicates a vector pointing horizontally from the seismometer in the direction of the wind turbine. 


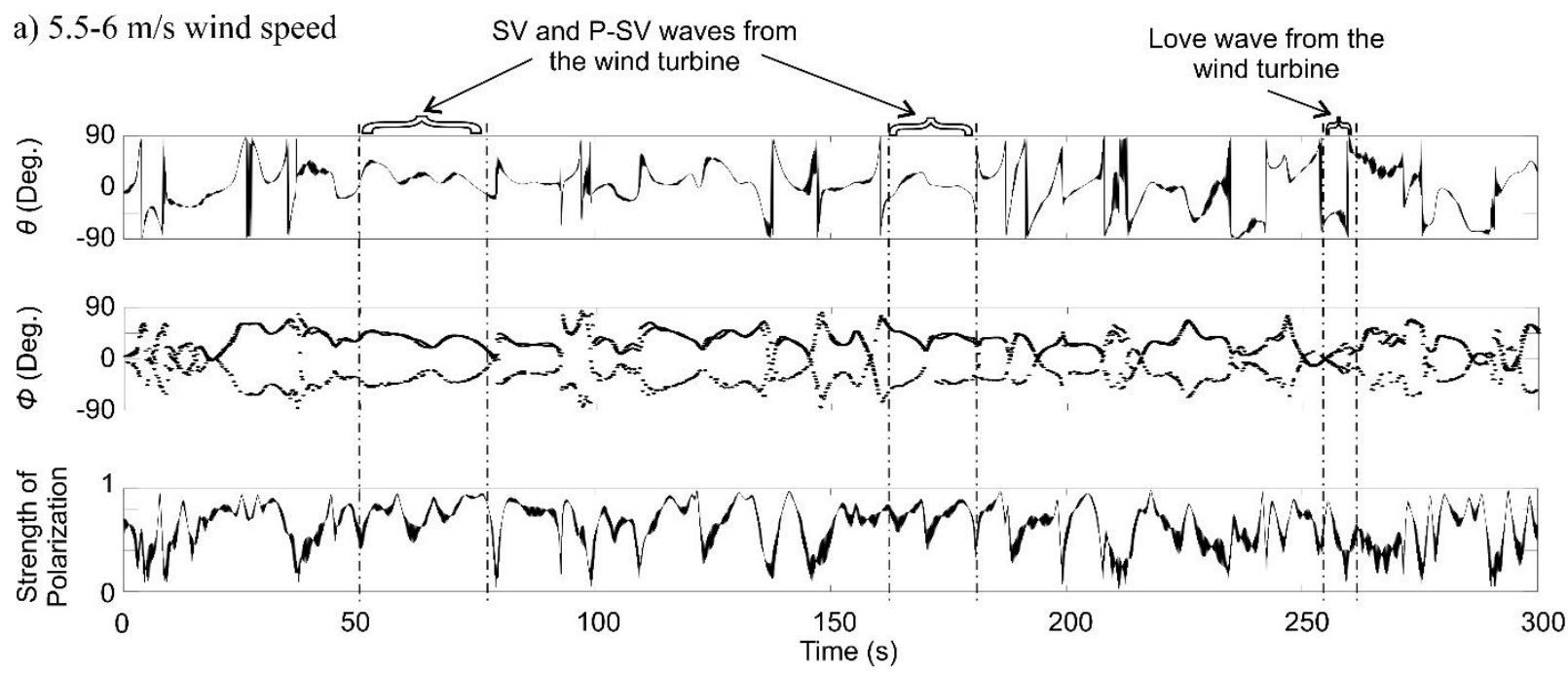

b) $1-1.5 \mathrm{~m} / \mathrm{s}$ wind speed
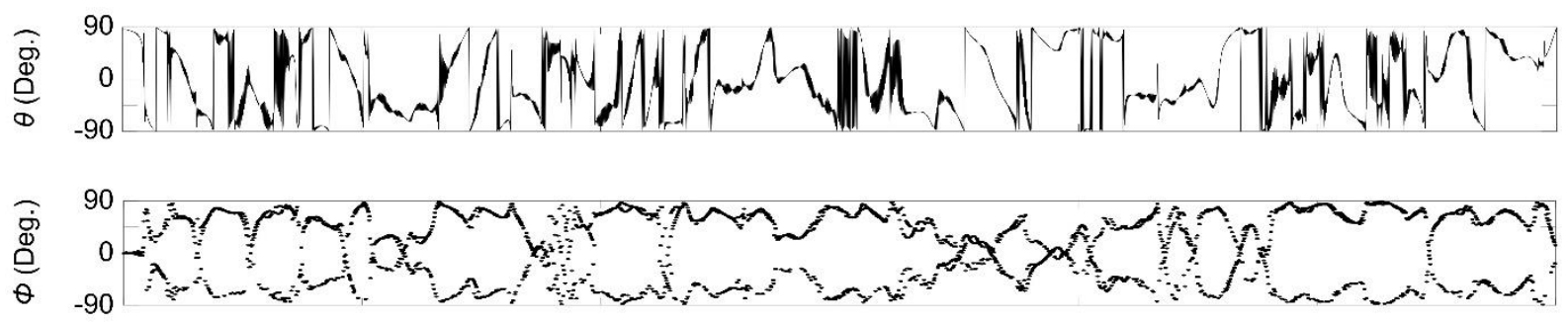

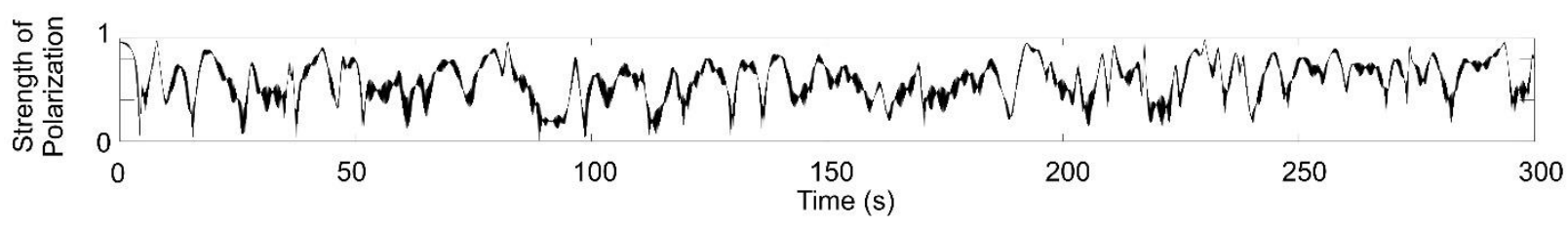

Figure 6: Results from performing polarization analysis for data recorded on a 6TD seismometer 190m from a Gaia-Wind 133 wind turbine between $7.5 \mathrm{~Hz}$ and $7.7 \mathrm{~Hz}$ and at wind speeds of a) $5.5 \mathrm{~m} / \mathrm{s}$ to $6 \mathrm{~m} / \mathrm{s}$ and b) $1 \mathrm{~m} / \mathrm{s}$ to $1.5 \mathrm{~m} / \mathrm{s}$. Annotations and vertical dashed lines highlight different waves seen within the data which correspond to the sketches in Figure 4 . A $0^{\circ}$ azimuth $(\theta)$ and dip $(\phi)$ indicate a vector pointing horizontally from the seismometer in the direction of the wind turbine. At low wind speeds the azimuthal and strength of polarization variations are wide with a general spread of directions and strength respectively. 


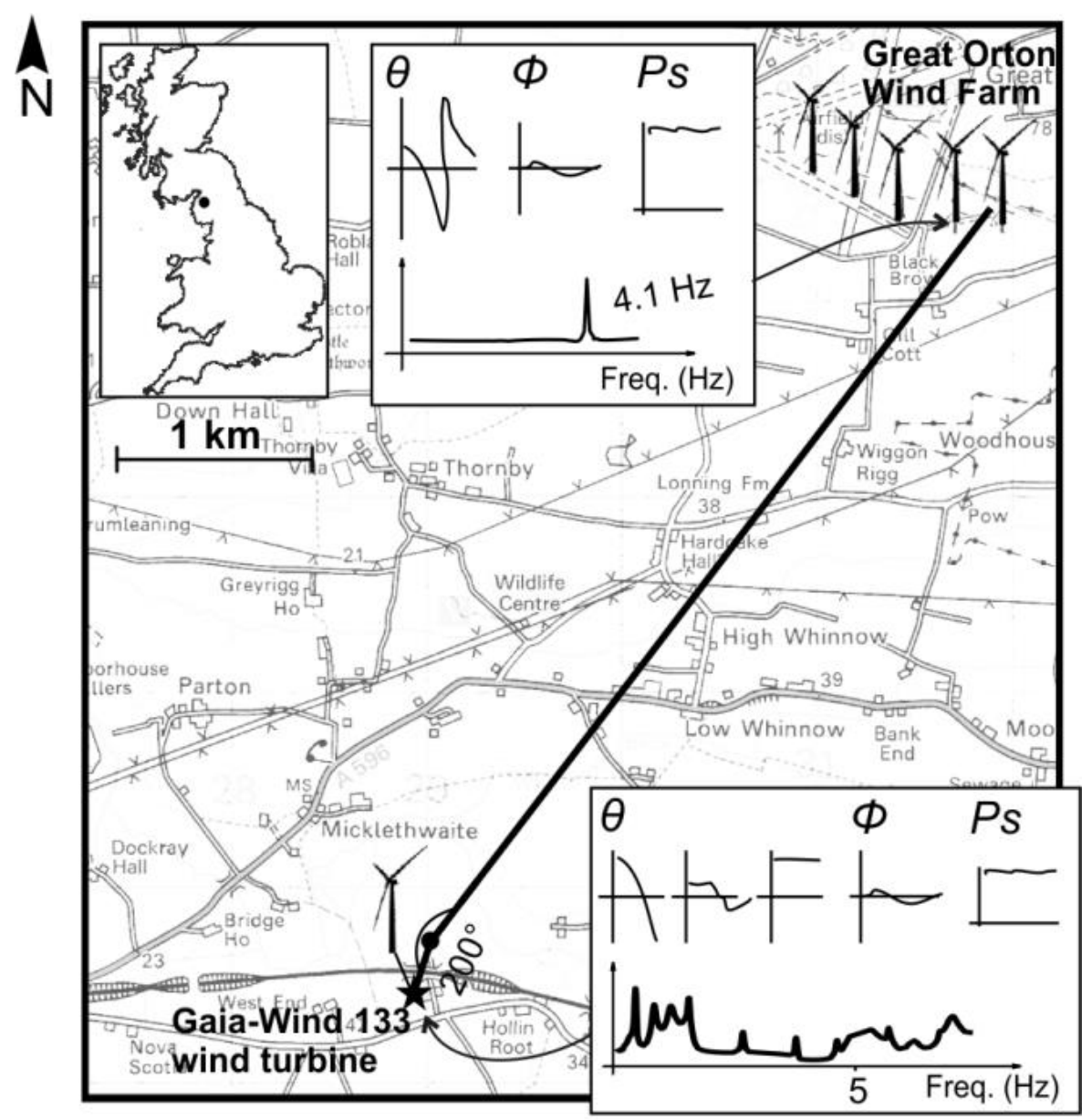

Contains data (c) Crown Copyright and Database Right 2015. Ordnance Survey (Digimap Licence)

Figure 7: The location and direction of the Great Orton wind farm relative to the wind turbine (star) and seismometer (circle). Inset (top left): Location of the site (black dot) in the UK. Inset (top middle and bottom right): Polarized signals and frequencies seen as a result of the Gaia-Wind 133 turbine and the Great Orton wind farm. 